\title{
UNBUILDING WALLS- German Pavilion 2018: From Death Strip to Freespace
}

\author{
CHRISTOPH KOMER \\ Woodbury University
}

For 28 years, Germany has been united - exactly as long as the Berlin Wall existed (1961-1989). On the occasion of this parallel, we were curating the exhibition "Unbuilding Walls" at the German Pavilion at the 16th International Architecture Exhibition in Venice.

The exhibition responds to current debates on nations, protectionism and division. The German Pavilion takes the parallel as an opportunity to explore the effects of division and the process of healing as a dynamic spatial phenomenon. With reference to "Freespace," the central theme of the Architecture Biennale, special focus will be given to outstanding examples of urban and architectural design that address aspects of division and integration. The exhibition design welcomes the visitor with the view of an almost oppressive, black, monumental wall as the first view from the entrance. After the eyes adjust to the dimmed light in the pavilion, guests start to realize that it is not a solid wall, but rather a fragmented assemblage of wall segments, scattered through the space, but distorted in a way that makes it look like a solid wall, using anamorphic effects. Once you start to move through the space, or other people are moving around you, you realize that the wall is fragmented and can be permeated. The activity of the visitor starts to unbuild the wall. The back of the wall fragments, not unlike the still existing segments of the Berlin Wall, are colorful, contrasting the stark blackness of the front. They display projects built or planned along the former iron curtain.

By analyzing architectural projects on the former border strip, the question of what happened on this unprecedented void in the middle of a new capital will be examined. The heterogeneity of the multitude of approaches, typologies, protagonists, and results show the breadth of architectural debates and solutions.

Taking the experience of the inner-German Wall as a starting point, the exhibition also examines historical as well as current barriers, fences and walls beyond Germany's specific national perspective. In the course of the preparations for Unbuilding Walls a journalist team travelled to border walls around the world. This work is shown at the German Pavilion as well.

The Wall of Opinions video installation documents the voices of people who live in the shadow of walls in Cyprus, Northern Ireland, between Israel and Palestine, the USA and Mexico, North and South Korea and at the European external border in Ceuta. 


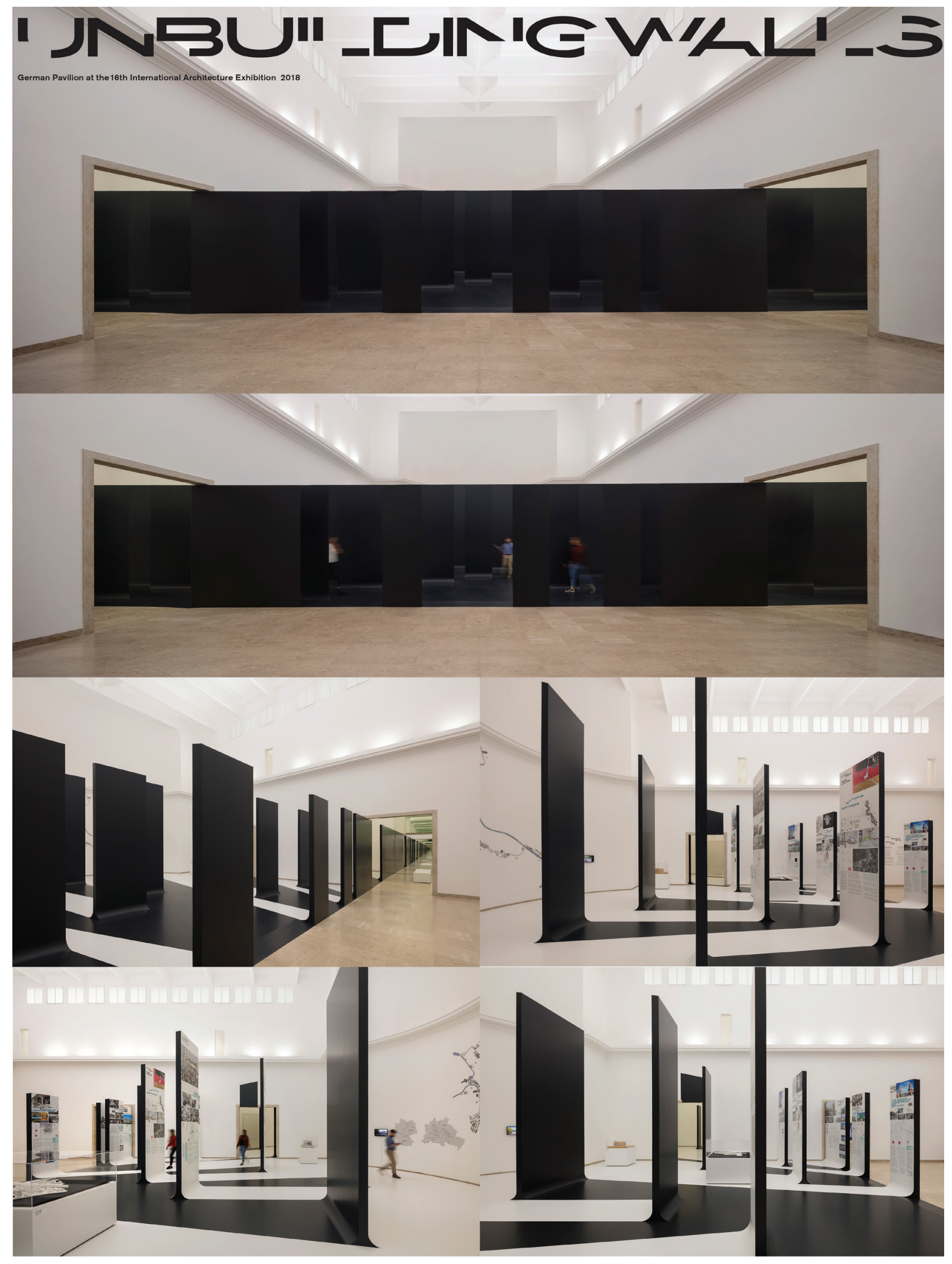

